\title{
O contexto da geometria no âmbito escolar: concepções e implicações na formação docente
}

\section{The context of geometry in school: conceptions and implications in teacher training}

\author{
Elenice Weber Stiegelmeier \\ Universidade Tecnológica Federal do Paraná (UTFPR), Departamento Acadêmico de Matemática, \\ Cornélio Procópio, PR, Brasil \\ elenicew@utfpr.edu.br \\ Vilsiele Cristina Marthos \\ Escola Educativa Centro Educacional, Ourinhos, SP, Brasil \\ vilsielex@yahoo.com.br
}

Glaucia Maria Bressan Universidade Tecnológica Federal do Paraná (UTFPR), Departamento Acadêmico de Matemática, Cornélio Procópio, PR, Brasil glauciabressan@utfpr.edu.br

\section{Informações do Artigo}

(c) (i) \&)

Histórico do Artigo

Submissão: 25 de agosto de 2018.

Aceite: 26 de setembro de 2018.

\section{Palavras-chave}

Geometria

Ensino de Matemática

Formação docente

\section{Resumo}

O presente trabalho busca discutir como, nas aulas de matemática da Educação Básica, é praticada a Geometria Euclidiana. A metodologia de pesquisa utilizada foi a pesquisa exploratória, que compreende o levantamento bibliográfico e estudos de casos com professores e alunos envolvidos no projeto. Os estudos de casos foram baseados na aplicação de atividades práticas aos alunos do $6^{\circ}$ ano do Ensino Fundamental II e $2^{\circ}$ ano do Ensino Médio, considerando o contexto da geometria no âmbito escolar. Nesse processo, apresentam-se alguns aspectos relevantes sobre ensino de Geometria Euclidiana na Educação Básica, a problemática acerca da forma como a geometria vem sendo trabalhada nas escolas e as implicações da formação docente neste processo. A partir dos dados levantados, conclui-se que o ensino de geometria deve buscar valorizar as construções, tornando-as significativas para o estudante e, ainda, a formação continuada dos docentes e o uso adequado de metodologias contribuem significativamente para a aprendizagem dos estudantes.

\section{Keywords}

Geometry

Mathematics Teaching

Teacher training

\section{Abstract}

The present work aims to discuss how Euclidean Geometry is practiced in Basic Mathematics classes. The research methodology used was an exploratory research, which involved the bibliographic survey and the case studies with teachers and students involved in the project. The cases studies were based on the application of practical activities to students of the 6th year of Elementary School II and of the 2st year of High School, considering the context of geometry in the school scope. In this process, we present some relevant aspects about the Euclidean Geometry teaching in Basic Education, the problematic about how the geometry is being worked in schools and the implications of teacher training in this process. Based on the data collected, we concluded that geometry teaching should seek to value constructions, making them meaningful to the student, and also, the continuing teachers training and the appropriate use of methodologies contribute significantly to students' learning. 


\section{Introdução}

Um dos temas que vem sendo discutidos dentro dos currículos de matemática é o ensino de geometria. Existe uma grande preocupação entre os professores e os pedagogos em como esse conteúdo vem sendo trabalho em sala de aula desde as séries iniciais ao ensino médio. Além disso, qual a concepção dos professores neste processo e as implicações no ensino de geometria.

A partir do movimento da Matemática moderna, por volta de 1950, observa-se que o ensino de Matemática passou a enfatizar o simbolismo e a exigir dos estudantes maiores abstrações, distanciando-se da vida real. Com isso, nota-se que o estudante egresso da Educação Básica, a partir desse currículo, apresenta lacunas em relação aos conteúdos de geometria, uma vez que não consegue relacionar os tópicos abordados com a realidade, evidenciando que, quando a geometria é bem compreendida, auxilia o estudante a perceber semelhanças, diferenças e a solucionar problemas (LOBO, 2004).

Segundo Fucks (1970), a Matemática moderna praticamente excluiu o ensino de geometria, enfatizando o simbolismo e uma terminologia excessiva. Nesse sentido, o baixo desempenho em geometria, por parte dos estudantes, é resultado, muitas vezes, da utilização de práticas pedagógicas que não atendem às expectativas dos estudantes, ressaltando o abismo existente entre o modo como docentes e estudantes percebem a Matemática.

Morelatti e Souza (2006) diagnosticaram, também, defasagens de aprendizagem na geometria em um trabalho realizado com os estudantes dos Centros Específicos de Formação e Aperfeiçoamento do Magistério (CEFAM), de Presidente Prudente, SP. Segundo esses autores, as dificuldades se intensificaram com o movimento da Matemática moderna, quando o ensino de geometria foi reduzido significativamente dos currículos escolares. Como consequência, o que se percebe hoje é que o estudante com um ensino defasado de geometria não tem estímulos para observar, perceber semelhanças, diferenças e para identificar as regularidades no seu dia a dia.

Ausubel, Novak e Hanesian (1980) já destacavam que o assunto a ser aprendido deve fazer algum sentido ao estudante, isto é, a aprendizagem precisa ser significativa e estar relacionada com os conceitos relevantes existentes em sua estrutura cognitiva. Quando o conteúdo é contextualizado, o docente consegue dar um significado real ao que é ensinado, despertando novos caminhos para os estudantes e, também, para si. "Este novo campo da Matemática, sob a faceta pedagógica é capaz de possibilitar descobertas e a paixão pelo aprendizado desta ciência" (SILVEIRA FILHO, 2006, p. 17). 
Nesse sentido, a contextualização pode ser um recurso útil para estabelecer relações entre o conteúdo proposto e a realidade histórico-social. Uma vez que

[...] torna-se cada vez mais evidente a necessidade de contextualizar o conhecimento matemático a ser transmitido ou construído, não apenas inserindo numa situação problema, ou numa abordagem dita "concreta", mas buscando suas origens, acompanhando sua evolução, explicitando sua finalidade ou seu papel na interpretação e na transformação da realidade para a qual o estudante se depara e/ou de suas formas de vê-la e participar dela (FONSECA, 2005, p. 7).

Por outro lado, o docente deve estar aberto a novas metodologias de ensino e experiências a fim de perceber a beleza e a importância que o ensino de geometria possui para a formação do cidadão e para o desenvolvimento do pensamento geométrico da criança nos anos iniciais do Ensino Fundamental. Esse pensamento permite à criança compreender e representar, de forma organizada, o mundo em que se encontra.

Fainguelernt (1999) destaca que o estudo da geometria é fundamental para o desenvolvimento do pensamento espacial e do raciocínio ativado pela visualização, recorrendo à intuição, à percepção e à representação, que são habilidades essenciais para a leitura do mundo e para que a visão da Matemática não fique distorcida. Vale destacar que, historicamente, a álgebra é abordada nas escolas com mais ênfase, por se tratar de conteúdos que contém algoritmos, regras, sendo sistematizados e abordados com frequência e rigor pelos docentes.

Nesse sentido, Pavanelo (1993) argumenta que:

A ausência do ensino de geometria e a ênfase no da álgebra pode estar prejudicando a formação dos estudantes por privá-los da possibilidade do desenvolvimento integral dos processos de pensamentos necessários à resolução de problemas matemáticos (PAVANELO, 1993, p. 16).

Portanto, é essencial resgatar o ensino da geometria, como uma das áreas fundamentais da Matemática e, para isso, são necessárias pesquisas na área que se dediquem à reflexão, à elaboração, à implementação e à avaliação de alternativas, que busquem superar as dificuldades encontradas na abordagem desse tema, tanto na escola básica como em níveis superiores de ensino.

Diante do exposto, o presente trabalho tem como objetivo principal discutir o ensino de geometria praticado nas escolas e as implicações da formação docente nesse processo. A indagaçãomestra orientadora do presente estudo tem a seguinte formulação: "Como nas aulas de matemática da Educação Básica do Brasil é praticada a Geometria Euclidiana?" 
As questões de pesquisa que desdobram essa indagação-mestra correspondem aos seguintes objetivos específicos que norteiam o presente trabalho. Cabe, então, analisar a trajetória do ensino de Geometria Euclidiana na Educação Básica; identificar lacunas no ensino e na aprendizagem da Geometria Euclidiana nas séries iniciais e investigar a formação docente nesse processo.

\section{Referencial teórico}

\section{1 ensino de geometria}

O ensino de geometria é fundamental para a compreensão da realidade, favorecendo a integração da Matemática a outras áreas do conhecimento como Ciências, Geografia, Arte, entre outras.

De acordo com a Base Nacional Comum Curricular (B.N.C.C.), espera-se que, nas séries iniciais, os estudantes identifiquem objetos, estabeleçam referências, desloquem objetos e construam representações, obtendo ampla visão do cotidiano. Já nas séries finais, busca-se consolidar e ampliar as aprendizagens, de modo que o estudante possa reconhecer condições e aplicar nas demonstrações, favorecendo o raciocínio lógico dedutivo (BRASIL, 2015a).

Durante muito tempo, tal percepção fundamentou-se na organização do ensino escolar da geometria elementar, dotando-a de um caráter ostensivo. Basta mostrar os objetos geométricos para que os reconheçam; basta enunciar suas propriedades para que os estudantes se apropriem delas. Porém, surge o questionamento: O que veem as crianças quando se mostra, por exemplo, uma figura geométrica?

Os psicólogos vêm identificando, há várias décadas, que os estudantes incluem aspectos não essenciais das figuras geométricas ao contextualizá-las, em função das condições em que aprenderam. Assim, se os lados de um quadrado não são paralelos às margens do papel ou quadro-negro em que é desenhado, a figura corre o risco de ser vista como um losango, devido à orientação adquirida.

Uma alternativa para melhorar o ensino da geometria seria propor a realização de atividades que poderiam proporcionar um contexto funcional para desenvolver o conhecimento das figuras geométricas através de processos de antecipação e de verificação. Assim, o processo de busca de conhecimentos prévios e de construção das formas geométricas no Ensino Fundamental I se tornariam ferramentas facilitadoras e de embasamento no processo de aprendizagem. 
Através da reflexão sobre o ensino da geometria na escola primária, uma série de problemas podem ser elencados, tais como:

- Preparar a passagem da geometria da observação, de comprovação empírica de relações para a geometria dedutiva, na qual a validade das proposições é sustentada pela coerência do raciocínio. Por exemplo, como passar da verificação de que ao justapor os três ângulos internos de um triângulo se obtém um ângulo de 180 graus à conclusão de que isso deve acontecer necessariamente em qualquer triângulo?

- Compatibilizar o caráter variável, aproximado, dos resultados obtidos empiricamente, com o caráter único, exato, dos resultados obtidos através do cálculo. Por exemplo, os valores obtidos para a área de um triângulo contando quadradinhos, com o valor obtido aplicando a fórmula a partir de medidas dadas de base e altura. Dito de outra maneira, o que se questiona é o papel da medição na verificação de equivalências Matemáticas. Por exemplo, no $2^{\circ}$ ano, pede-se que as crianças antecipem o valor do perímetro através do cálculo e depois, então, meçam para verificar a exatidão de sua antecipação. Assim, o que acontece se os resultados do cálculo e da medição não coincidir? Que acontece se o cálculo e a medição se repetir várias vezes?

- Garantir a compreensão dos procedimentos algoritmizados que os estudantes devem aprender? É evidente que a repetição de sua execução, até memorizar a sequência de ações que contém tal procedimento, não é suficiente. Porém, pelo que substituir essa estratégia de ensino?

- Coordenar a conceitualização dinâmica dos objetos geométricos (vinculados, por exemplo, ao traçado de Figuras) com sua conceitualização estática (vinculada a sua apresentação ostensiva)?

- Como organizar a passagem da linguagem natural, para referir-se às relações espaciais, até a linguagem Matemática, sem gerar rupturas violentas e possibilitando a apropriação sintática e semântica da linguagem Matemática, de modo que os estudantes possam utilizá-la para expressar seus conhecimentos?

- Como relacionar as aquisições no âmbito das relações espaciais com as aquisições no domínio das relações numéricas? Em que medida os progressos em um destes âmbitos podem facilitar ou obstaculizar a aprendizagem dos outros? (PARRA; SAIZ, 1996, p. 255).

Panizza (2006), em seu trabalho, já destacava que a geometria, na Educação Básica, se reduz à memorização dos nomes das figuras e mapas geométricos para o cálculo de áreas e volumes; enquanto deveria priorizar o saber funcional, que faz uso de esquemas e modelos que explicitam o que necessita ser resolvido, aquele que considera a cognição como aspecto principal na análise das variáveis envolvidas, na reestruturação mental e previsão dos resultados.

Portanto, a discussão dos problemas apresentados no ensino da geometria é o primeiro passo para a construção de novas metodologias, baseadas nos anseios dos alunos e professores, fazendo com que, assim, o ensino de geometria envolva diversos contextos que passam pela observação, comparação, reconhecimento, construção e finalmente interpretação, de acordo com o que se deseja resolver ou aplicar. 


\subsection{Reflexão sobre a prática docente}

No ensino da geometria na escola primária, há indícios de que a formação inadequada do docente é um dos fatores principais para as lacunas nos assuntos que surgem no Ensino Médio (LORENZATO, 1995; PAVANELLO, 1993), "pois a falta de formação do professor e de uma metodologia adequada para o ensino da Geometria pode ser um empecilho muito grande na obtenção de resultados positivos no ensino da Geometria "(REZENDE, 2015, p. 4).

Diante desse cenário, faz-se necessário repensar e reestruturar a formação docente, no que diz respeito ao ensino da Matemática e, mais especificamente, da Geometria, "tendo em vista que uma sociedade em constantes mudanças impõe a escola responsabilidades diferenciadas de ensinar" (CRESCENTI, 2008, p. 88). Logo, o professor deve estar preparado para essas mudanças e, para isso, precisa

[...] ter conhecimento sobre o conteúdo, sobre sua importância para os alunos e para a sociedade e sua aplicabilidade a outras áreas do conhecimento e ao cotidiano; usar metodologias adequadas a cada assunto; [...] usar adequadamente materiais e recursos; envolver o aluno na própria aprendizagem, incentivar sua participação, possibilitar a comunicação e a troca de informações entre professor-aluno e alunoaluno (CRESCENTI, 2008, p. 87).

No entanto, para se avançar nesse processo, o professor precisar ter clareza que, para o ensino da geometria, existem diversas formas de abordar os conteúdos, sendo necessário que o estudante percorra etapas na compreensão das formas básicas, desde as construções mais simples até as mais complexas. Os alunos precisam visualizar as propriedades e os pontos principais de forma contextualizada e natural, respeitando cada fase da aprendizagem para que assim, nas séries finais, sejam capazes de interpretar e de utilizar as ferramentas adequadas na resolução dos problemas. Dessa forma, "o professor deve dar tempo para o aluno descobrir algumas relações, exercendo o papel de observador e mediador percebendo o momento para intervir, questionando os alunos e assim criando com eles os conceitos pré definidos" (RABAIOLLI; 2013, p. 24).

E, ainda, Fainguelernt (1999) ressalta que "o ensino da Geometria deveria começar desde cedo e continuar, de forma apropriada, através de todo o currículo de Matemática" (p. 21), sendo fundamental que os professores nesses níveis de ensino busquem "[...] alternativas metodológicas com diversos recursos que auxiliarão no processo de ensino e de aprendizagem" (RABAIOLLI, 2013, p. 25).

Assim, visando ao resgate da geometria em sala de aula, Crescenti (2008) considera que 
se faz necessário, para que o ensino de Geometria possa estar presente nas salas de aula e possa contribuir para que os alunos aprendam de forma significativa, que o professor de Matemática tenha: uma formação básica que capacite os futuros professores na aquisição do conhecimento geométrico nas disciplinas específicas do curso de licenciatura, para que possam ensiná-los com segurança, [...] e uma formação continuada que possibilite um acompanhamento dos professores iniciantes por profissionais mais experientes de forma a auxiliá-los no início de sua prática em sala de aula [...] com cursos voltados à atualização dos conhecimentos científicos/metodológicos; que atenda as necessidades e interesses dos professores em seu local de trabalho; que promova a reflexão sobre a prática e a troca entre os pares (CRESCENTI, 2008, p. 93).

As Diretrizes Curriculares Nacionais para os Cursos de Bacharelado e Licenciatura em Matemática apontam nesse sentido, visto que está previsto que o aluno egresso do curso de formação inicial seja um profissional consciente do seu papel social como educador e tenha capacidade para se inserir em diversas realidades com sensibilidade para interpretar as ações dos educandos (BRASIL, 2002).

Vale destacar que a Resolução CNE/CP n 02/2015, que define as Diretrizes Curriculares Nacionais para a formação inicial em nível superior e para a formação continuada, surge para reestruturar os currículos dos cursos de licenciatura visando promover a articulação entre a teoria e a prática no processo de formação docente e, também, a atuação e a participação na organização e na gestão de sistemas de Educação Básica. Dessa forma, os cursos de graduação devem buscar integrar os conhecimentos adquiridos nas licenciaturas em três eixos formadores: o eixo formador do conhecimento matemático, o eixo formador do educador e o eixo formador do educador matemático (BRASIL, 2015b).

Para Pimenta (2006), é essencial que a formação docente associe teoria e prática uma vez que "[...] a prática seria a educação em todos os seus relacionamentos práticos e a teoria seria a ciência da Educação" (PIMENTA, 2006, p. 99). A fim de consolidar essa metodologia, é necessário que momentos de discussão e reflexão da práxis docente estejam sempre presentes, pois

[...] a reflexão é essencial para a construção da identidade docente e para o seu desenvolvimento profissional, pois permite que o professor seja capaz de transformar sua prática e se constituir como sujeito autônomo que pode suscitar mudanças no contexto educacional (PIMENTA; GHEDIN, 2002, p. 7).

Assim, para que a reflexão de fato ocorra, vem sendo amplamente discutida a formação continuada de professores. Fávero, Tonieto e Roman (2013) relatam que 
há um consenso entre os professores e dirigentes escolares que é necessário "educar os educadores", pois os saberes racionais que foram aprendidos nos processos formativos não são suficientes para enfrentar a complexidade e a diversidade dos problemas que o trabalho docente exige. É necessário e urgente, em qualquer área de atuação, refletir sobre novas formas de exercer os saberes necessários para a prática profissional. No que se refere ao trabalho docente, a reflexão na e sobre a prática possibilita que o educador reveja sua própria atuação (p. 277).

Logo, "analisar a formação continuada de professores a partir do paradigma do professor reflexivo" (FÁVERO; TONIETO; ROMAN, 2013, p. 285) é uma alternativa promissora para enfrentar os desafios do cotidiano da prática docente. A prática é o papel central de todo currículo, uma vez que se torna o espaço de construção do pensamento prático do professor.

É neste cenário que a própria docência se torna objeto de investigação e a perturbadora dicotomia entre teoria e prática, que frequentemente perpassa os discursos educacionais, poderá ser superada, pois pensar a formação dos educadores a partir do paradigma do professor reflexivo implica assumir o desafio de refletir na e sobre a ação. Enfrentar tal desafio certamente não será tarefa fácil, pois requer novas posturas para enfrentar os próprios processos formativos e novas compreensões da própria identidade do educador (FÁVERO; TONIETO; ROMAN, 2013, p. 284-285).

Dessa forma, a formação de professores, tanto nos cursos de graduação como nos cursos de formação continuada, deve refletir sobre as novas formar de exercer os saberes necessários para a prática profissional, visando oportunizar aos estudantes um ensino de qualidade que contribuirá para sua formação acadêmica, social e ambiental.

Portanto, o resgate da geometria precisa acontecer de forma gradativa, iniciando com ajustes nos currículos dos cursos de graduação, para dar uma sólida formação matemática e didática aos futuros professores, bem como cursos de formação continuada aos docentes da rede básica de ensino. A partir dessas ações, o ensino de geometria e, também, o ensino da Matemática poderá passar a ser mais eficiente, uma vez que o professor terá uma sólida formação dos conteúdos matemáticos necessários para a docência nesses níveis de ensino, colaborando para a melhoria na Educação Básica de forma geral.

\section{Metodologia}

Para este estudo, como metodologia de pesquisa, foi realizada uma pesquisa exploratória, que envolve o levantamento bibliográfico e estudos de casos com professores e alunos participantes no projeto. Os estudos de casos foram baseados em entrevistas e aplicação de atividades práticas considerando o contexto da geometria no âmbito escolar. 
As atividades de pesquisa foram realizadas na Escola Educativa Centro Educacional localizada na cidade de Ourinhos, do Estado de São Paulo, e teve início com o trabalho de formação de professores que ministravam as disciplinas de matemática no Ensino Fundamental I e II, partindo das inquietações e dificuldades dos professores em entender e ensinar geometria aos estudantes de forma eficiente. Inicialmente, foram realizadas entrevistas em um grupo de 12 (doze) professores para realizar um levantamento diagnóstico de como a geometria vem sendo abordada em sala de aula. Através desse levantamento, foram realizados diversos encontros pedagógicos com esse grupo de professores onde buscou-se discutir novas formas de se ensinar geometria.

Os alunos envolvidos na pesquisa foram divididos em um experimento com dois grupos: um grupo experimental e um grupo controle. O grupo experimental foi composto pelos alunos atendidos por professores que participavam do projeto, e o grupo controle foi composto por alunos oriundos de outras escolas públicas.

Visando à continuidade e ao aprimoramento do projeto, foram realizadas atividades com um grupo de 18 (dezoito) alunos do $6^{\circ}$ ano do Ensino Fundamental II e 15 (quinze) alunos do $2^{\circ}$ ano do Ensino Médio, a fim de identificar suas dificuldades frente à Geometria Euclidiana e algumas possíveis lacunas existentes nesses níveis de ensino.

Diante disso, foi realizada uma análise diagnóstica qualitativa que colabore na elaboração de orientações metodologia adequadas, como forma de minimizar as dificuldades, ampliar a contextualização da geometria, aproximando-a da realidade dos estudantes, na busca por um ensino inovador, que priorize o sequenciamento lógico da geometria e que obtenha, como resultado final, a consolidação dos conteúdos abordados.

\section{Resultados e discussões}

A partir de encontros pedagógicos com o grupo de docentes que ministravam as disciplinas de Matemática e professores das séries iniciais da escola, foi realizado um levantamento das dificuldades encontradas no ensino da geometria e, também, foram compartilhados os pontos positivos desse em sala de aula.

As dificuldades dos alunos em relação à Geometria, destacadas pelos docentes, foram: construir figuras, identificar as propriedades de cada figura, entender o que o enunciado pede, manusear os instrumentos de construções. Além dessas dificuldades, os professores destacaram a dificuldade 
que eles próprios possuem no uso de material concreto para o estudo das figuras espaciais e de como abordar a criança para corrigi-la quando, também, não se tem formação adequada para isso.

Com relação aos pontos positivos do ensino da Geometria, os professores destacaram: os estudantes já têm muitos conceitos sobre vários assuntos de geometria, a geometria deve priorizar a visualização para ser melhor compreendida e a geometria pode ser encontrada em todos os lugares no cotidiano, o que facilita a explicação dos conceitos. E, ainda, a partir de discussões com o grupo de professores, constatou-se que diversas dificuldades apresentadas pelos alunos do Ensino Fundamental II são reflexo da formação obtida nas séries iniciais.

Assim, iniciou-se um trabalho voltado aos docentes das séries iniciais, ou seja, com os docentes que atuam no Ensino Fundamental I, com o objetivo de verificar se o ensino da Geometria Euclidiana está sendo realizado de forma adequada nesses níveis de ensino, uma vez que a construção dos conceitos nessa fase contribui de forma significativa para o ensino de geometria nas séries finais.

A partir desse levantamento, teve-se a iniciativa de se criar um projeto voltado à formação docente para o ensino da geometria, visto que grande parte das dificuldades elencadas na pesquisa aponta para a falta de preparo do docente. Diante disso, iniciou-se um curso de formação continuada voltado aos docentes do Ensino Fundamental I e II com o objetivo de aprimorar a didática no ensino de geometria e buscar melhores resultados nas séries finais.

A primeira parte do projeto foi voltada à formação docente, ou seja, à formação docente para o ensino de geometria, com o uso de materiais manipuláveis, metodologias diferenciadas de ensino. Nessa etapa, foram realizados encontros periódicos com os professores da escola a fim de discutir novas formas de como se ensinar geometria. Na segunda etapa, foi realizado um acompanhamento dos estudantes das séries iniciais, os quais eram atendidos por professores que participavam do projeto. Nessa fase, durante os encontros pedagógicos, os professores compartilhavam as experiências levadas para a sala de aula, a fim de refletir sobre a prática docente e buscar o aprimoramento das metodologias utilizadas.

A terceira etapa do projeto foi realizada após três anos de seu início, acompanhando e observando os estudantes pertencentes ao grupo experimental. A fim de verificar a eficiência do projeto, foram aplicadas atividades de geometria aos alunos que foram acompanhados pelos professores que receberam a formação, os quais chegaram ao $6^{\circ}$ ano (grupo experimental). Para a validação do 
projeto, essas mesmas atividades foram aplicadas em alunos oriundos de outras escolas, que não tiveram contato com os docentes do projeto (grupo controle).

Nas atividades propostas aos alunos do $6^{\circ}$ ano do Ensino Fundamental II, o estudante precisava demonstrar conhecimentos sobre paralelismo de retas, retas concorrentes e sua classificação aos pares, retângulo e suas propriedades básicas, o conceito de perímetro de um retângulo. $\mathrm{O}$ objetivo, neste momento, é que os estudantes façam o desenho, o gráfico, ou somente respondam descritivamente a questão. Foram aplicadas, para um grupo de 18 estudantes, quatro atividades diferentes e analisados os erros e os acertos.

Dos resultados obtidos, em média $25 \%$ desses estudantes resolveram as questões corretamente, interpretando e organizando o raciocínio, buscando construções e se envolvendo nos problemas. Constatou-se que esse grupo de estudantes faz parte do grupo experimental, ou seja, teve contato com professores que participaram do projeto de formação continuada em geometria desde o Ensino Fundamental I. Enquanto os demais 75\% dos estudantes, oriundos de outras escolas públicas, apresentaram dificuldade na interpretação dos problemas, se perderam na organização dos dados, na identificação da figuras, suas propriedades e cálculos. Isso evidência que, mesmo tendo estudado esse conteúdo no $6^{\circ}$ ano, a fixação ficou defasada, requerendo um tempo maior para compreender efetivamente o conteúdo.

A partir da análise das respostas dos alunos do grupo experimental, constataram-se defasagens de conteúdos anteriores provenientes do Ensino Fundamental I em relação à geometria espacial, fato que corrobora com a pesquisa e precisa ser aprimorado junto aos professores. Já na geometria plana, assunto com o qual os estudantes tiveram contato desde muito pequenos, com a utilização de material concreto, observou-se êxito nas atividades propostas.

Assim, após análise das atividades realizadas aos estudantes do $6^{\circ}$ ano do Ensino Fundamental II e acompanhando a trajetória desses estudantes, percebe-se que os estudantes que tiveram contato com os professores que participaram do projeto, os quais estavam comprometidos e preparados para o ensino da geometria, fazendo uso de materiais adequados desde as séries iniciais, puderam visualizar e compreender as formas simples e complexas das figuras e conseguiram resolver as atividades de forma adequada, concluindo os exercícios, sem esbarrar na álgebra. E, ainda, mostraram também tranquilidade e menos dificuldade diante dos obstáculos. Contudo, os estudantes oriundos de outras escolas não obtiveram o mesmo desempenho, evidenciando a falta de pré-requisitos para interpretar e responder as questões propostas. 
A partir dessa análise, concluiu-se que, para se obter um ensino de geometria eficiente, faz-se necessário que o docente do Ensino Fundamental I apresente os conceitos de forma sistematizada, aproveitando os conhecimentos prévios dos estudantes e avançando nos conteúdos de geometria de forma gradual, tornando-a desafiadora, fazendo com que a Matemática, e consequentemente a geometria, apresente-se de forma menos traumática aos estudantes quando iniciam os estudos no $6^{\circ}$ ano do Ensino Fundamental II. Vale destacar que, durante esse processo, o professor deve estar em constante mudança visando criar condições para que a aprendizagem de fato aconteça (NÓVOA, 2002a).

$\mathrm{Na}$ segunda fase do projeto, também, foi realizado um mapeamento das dificuldades no aprendizado de geometria em estudantes do Ensino Médio com o objetivo de reconhecer os conceitos necessários e discutir junto aos docentes quais as práticas que podem vir a contribuir com o ensino de geometria nesse nível de ensino.

Nesse grupo de estudantes, espera-se que eles consigam organizar a resolução dos problemas de acordo com os conteúdos estudados nas séries anteriores, interpretando os enunciados, com base em conceitos, pontuando as resoluções, identificando qual conceito usar e a forma correta de desmembrar o exercício para facilitar sua compreensão. Isso só será possível se o estudante conhecer efetivamente os conceitos de geometria aplicados.

As atividades propostas foram aplicadas a um grupo de 15 estudantes do $2^{\circ}$ ano do Ensino Médio da Escola Educativa Centro Educacional. Esse grupo de estudantes é formado por alunos que tiveram contato com os professores que participaram do projeto oriundos do Ensino Fundamental II e, também, estudantes que chegaram de outras escolas. Os conteúdos abordados nas questões estavam relacionados ao conceito de bissetriz, soma dos ângulos internos de um triângulo, propriedades do triângulo isósceles, semelhança de triângulos, Teorema de Pitágoras, fórmulas das áreas do triângulo e do círculo.

Através das respostas obtidas com os alunos do $2^{\circ}$ ano do Ensino Médio, constatou-se que em média $22 \%$ dos alunos resolveram de forma satisfatória as questões apresentadas, porém, observou-se que, dentre os estudantes que acertaram, ainda falta certo cuidado na escrita da resposta, coerência nas explicações e melhor organização dos resultados. Os demais alunos, 78\%, não resolveram de forma satisfatória, alguns nem tentaram resolver as questões, alegando falta de conhecimentos necessários, ou tentaram mas não resolveram a questão corretamente, errando principalmente nos cálculos algébricos e na interpretação das figuras geométricas. 
Assim, fica evidente o papel do professor nesse processo, uma vez que observou-se a necessidade do professor trazer para a sala de aula novas metodologias que priorizem a interpretação geométrica dos conteúdos abordados nesses níveis de ensino, visto que os alunos apresentam dificuldades básicas de geometria na construção, interpretação e resolução de problemas.

Ao propor as atividades aos estudantes do Ensino Fundamental Il e Ensino Médio, observouse diferentes reações de acordo com a fase de escolaridade na qual os estudantes se encontravam. A partir de uma entrevista realizada, após a aplicação das atividades pelo professor, constatouse que os estudantes do $6^{\circ}$ ano do Ensino Fundamental II demonstraram maior entusiasmo frente aos desafios propostos, mesmo esbarrando em alguns pontos. No entanto, os estudantes do $2^{\circ}$ ano do Ensino Médio apresentaram dificuldades com a geometria principalmente na resolução de problemas, muitos têm medo de enfrentar, outros enfrentam, mas não com segurança e confiança, pois durante as séries anteriores foram surgindo lacunas ocasionando dúvidas e despreparo.

A partir das análises dos resultados, verificou-se que a formação continuada dos docentes refletiu de maneira positiva nos alunos pertencentes ao grupo experimental, e o professor do Ensino Fundamental I mostrou ser uma peça fundamental para a melhoria do ensino de geometria. Outro ponto que se destaca, nesta análise, é que o docente nunca está pronto, no sentido de que pesquisas e estudos devem fazer parte da rotina do professor, porque somente assim terão condições de atuar acompanhando as mudanças no contexto histórico do qual fazem parte, conscientes de seu papel na formação intelectual e social dos estudantes.

E, ainda, como já destacavam Parra e Saiz (1996), além de uma boa formação docente, devese refletir sobre qual a geometria deve-se ensinar na Educação Básica, visando aspectos relativos ao desenvolvimento da didática da matemática no mundo, analisando a situação atual do ensino de modo geral. Parra e Saiz (1996) ainda afirmam que o estudante precisa colocar em prática suas contextualizações, reflexões e seus questionamentos, sendo o professor imprescindível nesse processo, com a responsabilidade social de se fazer mais e melhor.

\section{Considerações finais}

O presente trabalho buscou trazer para discussão a problemática acerca da forma como a geometria vem sendo trabalhada nas escolas, identificando por meio de atividades as defasagens na compreensão desse assunto por parte dos alunos, ocasionada por lacunas que permeiam o processo de ensino. 
Destacou-se nesse estudo que o sucesso na compreensão da Matemática e, mais especificamente da geometria, está diretamente relacionado com a abordagem do docente aos diferentes temas, pois a aprendizagem adequada das construções geométricas no Ensino Fundamental I são de suma importância no desenvolvimento de cada estudante. Nesse sentido, o trabalho faz repensar a formação docente nos anos iniciais do Ensino Fundamental, identificando a necessidade de atualização continua que, certamente, proporcionará maior segurança na exploração das habilidades discentes.

Os resultados obtidos nesse trabalho mostraram-se satisfatórios, uma vez que, ao serem desenvolvidas as atividades das situações-problema sobre geometria com os alunos, demostrouse que a utilização de metodologias de ensino diferenciadas e professores com formação adequada fazem com que os estudantes passem a se relacionar melhor com a Geometria Euclidiana, tornandoos mais preparados para as séries posteriores.

Vale destacar que, a partir das análises realizadas, a formação continuada de professores passa a constituir um instrumento fundamental para se alcançar resultados melhores na educação, em especial ao ensino de geometria, uma vez que a formação continuada depende da experiência e da reflexão como instrumentos contínuos de análise. Nóvoa (2002b, p. 23) já destacava que "o aprender contínuo é essencial e se concentra em dois pilares: a própria pessoa, como agente, e a escola, como o lugar de crescimento profissional permanente". Nesse sentido, novas políticas devem ser implementadas a fim de dar suporte ao professor para que esse possa estar em constante aperfeiçoamento, pois nenhuma reforma educacional tem valor se a formação docente não for encarada como prioridade.

Portanto, para que o ensino de geometria seja eficiente, fica evidente a necessidade de escolas preparadas, que possam oferecer uma educação de qualidade, com espaços físicos e materiais adequados ao seu desenvolvimento. Além disso, torna-se primordial que a classe docente seja valorizada em seu contexto mais amplo, pois são grandes os desafios enfrentados, mas manter-se atualizado e desenvolver práticas pedagógicas eficientes faz desse profissional o diferencial necessário à profissão.

\section{Referências}

AUSUBEL, D.P.; NOVAK, J.D.; HANESIAN, H. Psicologia educacional. Rio de Janeiro: Interamericana, 1980. 
BRASIL. Diretrizes Curriculares Nacionais para os Cursos de Matemática, Bacharelado e Licenciatura. Diário Oficial da União de 5/3/2002, Seção 1, p. 15, 2002.

BRASIL. Base Nacional Comum Curricular. Brasília: CONSED/UNDIME/MEC, 2015a.

BRASIL. Resolução CNE/CP nº 02 de 2015. Diretrizes Curriculares Nacionais para a formação inicial em nível superior (cursos de licenciatura, cursos de formação pedagógica para graduados e cursos de segunda licenciatura) e para a formação continuada. Brasília, MEC, 2015b.

CRESCENTI, E. P. A formação inicial do professor de matemática: aprendizagem da Geometria e atuação docente. Práxis Educativa, Ponta Grossa, PR, v. 3, n. 1, p. 81 - 94, 2008.

FAINGUELERNT, E. K. Educação Matemática: representação e construção em geometria. Porto Alegre: Artes Médicas Sul, 1999.

FÁVERO, A. A.; TONIETO, C.; ROMAN, M. F. A formação de professores reflexivos: a docência como objeto de investigação. Educação, Santa Maria, v. 38, n. 2, p. 277-288, 2013.

FONSECA, M. C. F. R. O Sentido matemático do letramento nas práticas sociais. Presença Pedagógica. Belo Horizonte: Editora Dimensão, 2005.

FUCKS, W. R. Matemática Moderna. São Paulo: Polígon, 1970.

LOBO, J. da S. O Ensino de Geometria no Ensino Fundamental. ActaScientiae, Canoas, v. 6, p. 19-26, 2004.

LORENZATO, S. Por que não ensinar geometria? A Educação Matemática em Revista, Blumenau: SBEM, v. 3, n. 4, p. 3-13, 1995.

MORELATTI, M. R. M.; SOUZA, L. H. G. Aprendizagem de conceitos geométricos pelo futuro docente das séries iniciais do Ensino Fundamental e as novas tecnologias. Curitiba: UFPR, 2006.

NÓVOA, A. Formação de professores e trabalho pedagógico. Lisboa: Educa, 2002a.

NÓVOA, A. Os novos pensadores da educação. Revista Nova Escola. Edição nº 154, 2002b.

PANIZZA, M. Ensinar Matemática na Educação Infantil e nas séries iniciais: análise e propostas. Porto Alegre: Artmed, 2006.

PIMENTA, S. G.; GHEDIN, E. (Orgs.). Professor reflexivo no Brasil: gênese e crítica de um conceito. São Paulo: Cortez, 2002.

PIMENTA, S. G. O Estágio na Formação de Professores: Unidade Teoria e Prática? 7. ed. São Paulo: Cortez, 2006.

PARRA, C.; SAIZ, I. (Org.). Didática da Matemática: Reflexões Psicopedagógicas. 1. ed. Porto Alegre: Artmed, 1996. 
PAVANELLO, R. M. O abandono do ensino da geometria no Brasil: causas e consequências. Revista Zetetiké, Campinas, Ano 1, n. 1, p. 7-18, 1993.

RABAIOLLI, L. L. Geometria nos anos iniciais: uma proposta de formação de professores em cenários para investigação. 2013. 134 f. Dissertação (Mestrado Profissional em Ensino de Ciências Exatas) - Universidade do Vale do Taquari, Lajeado, 2013.

REZENDE, D. P. L. Ensino e aprendizagem de geometria: uma proposta para o estudo de polígonos nos anos finais do Ensino Fundamental. In: XIX Encontro Brasileiro de Estudantes de Pós-Graduação em Educação Matemática, 2015, Juiz de Fora. Anais XIX Encontro Brasileiro de Estudantes de Pós-Graduação em Educação Matemática, UFJF, 2015. p. 1-12.

SILVEIRA FILHO, J. O Novo Contexto da Matemática. Revistas das Faculdades Santa Cruz, v. 5, n. 2, 2006. 